\title{
Micro- and macro-dimensions in linguistic systems
}

\author{
Nicholas J. Enfield
}

\begin{abstract}
To understand the nature of linguistic systems, including their maintenance and change, one must consider them simultaneously both as something embodied in the individual and as being played out and observable in the larger social context. It is only at the micro-level that linguistic processes actually take place, but the consequences of these processes aggregate and conventionalize at the macro-level. The micro- and macro-dimensions of language have traditionally been studied separately, within separate linguistic traditions. However, the two are inter-dependent and inextricably linked in reality, and should be treated as such in our analyses of linguistic maintenance and change. The point is illustrated with reference to research on the phenomena of grammatical change and areal linguistics in mainland Southeast Asia.
\end{abstract}

\section{Introduction}

One way to think of a linguistic system is as a public set of conventions with a social locus, a community-wide system independent of any individual. From another view, the system is a private structure with a cognitive locus, fully housed in the brain of a single person. I argue that, first, it is necessary to recognize that these are quite different ideas of system, but second that it is both possible and desirable to simultaneously maintain both perspectives on what $a$ language is. The point is to be illustrated with reference to research on the phenomena of grammatical change and areal linguistics. 'This chapter begins with a discussion of the nature of individuals in social interaction, and consequences for our understanding of the nature of language. This is followed by an exploration of these issues with reference to a case of semantic and grammatical change in languages of the mainland Southeast Asia area (Enfield 2003). 


\section{Two assumptions about people in social interaction}

Two fundamental assumptions can be made as follows. First, there is "no telepathy" (Hutchins and Hazlehurst 1995: 54). People have no direct access to the minds of others. The fact that we understand the speech of our social associates arises not from us accessing the same form-meaning mappings, but from our each having constructed our own private hypotheses of form-meaning mapping which function as effectively the same - i.e. which do not give rise to detectable differences in communicative effect, assuming certain expectations. Our mental lexicons and grammars are no more than our individual hypotheses of how certain signs can be used to solve coordination problems in face-to-face interaction and in communication more generally (Schelling 1960; Lewis 1969; Hutchins and Hazlehurst 1995; Clark 1996). As long as our personal hypotheses of meaning are effectively identical, with respect to communicative function, then any substantive difference between what a speaker thinks she encodes with her words, and what a hearer thinks is being encoded cannot and need not be detected (Apresjan 1974: 14; Evans and Wilkins 2000).

The second assumption to be made at the outset is that of methodological individualism, the principle that the fundamental unit of any social process is the individual, and a satisfactory analysis of a given social process must be reducible to the participation and contribution of individuals (Schelling 1960; Lukes 1968; Nettle 1997; Hedström and Swedberg 1998). This follows from the assumption of no telepathy, and from the fact that individuals are physically discrete, mobile, and mortal. The insight of methodological individualism has enabled sociologists and others to model macro-level social processes in realistic ways, namely by conceiving of them in terms of the wants, needs, and actions of individuals, and showing how macro-level consequences can arise from micro-level "invisible hand" processes, whereby individuals act without necessarily foreseeing or intending the higher level results of their actions (Smith [1776] 1976; Schelling 1960; Keller 1994; Hedström and Swedberg 1998).

\section{From micro-systems to macro-system}

These points hold with respect to the social processes which give rise to what we call language on the one hand, and languages on the other. The idea of a language suggests a coherent system, whether it is housed pri- 
vately or publicly. But given the no telepathy and methodological individualism assumptions, if "languages" are systems, then they must firstly be systems housed in individual minds. When we talk about languages like English or Lao, we presuppose their existence in individual minds, but we are clearly referring to systems which are somehow consistent across individuals (despite the uniqueness of each individual's personal linguistic system or idiolect). Community-wide systems of convention we know of as languages could perhaps then be thought of as cases in which a large number of individuals have internalised and cognitively embodied effectively the same system. Is this the case? Leaving aside the problem of just to what extent these individually embodied systems are the same, it is clear that a language in this sense is not an empirically definable object transcending the individuals which provide the evidence for its existence. Rather, because of the existence of these individuals, with their highly convergent patterns of linguistic behaviour, we can conceive of large aggregations of conventional linguistic items as having just this individual-independent nature (Le Page and Tabouret-Keller 1985; Nettle 1999; Croft 2000; Enfield 2003). But no evidence of a language can be found without there being an individual human actively supplying an interpretation of some signal. ${ }^{2}$ The micro-level is that of the system as housed or embodied by individual speakers, while on the macro-level there is a community-wide consistency to the system observed.

\section{Micro-macro interaction in language change}

One area of linguistic research which is illustrative in exploring the need to maintain both the micro- and macro-perspectives of the linguistic system is language change. The very idea that languages change over time assumes a notion of languages as entities with historical continuity extending further than the history of individuals. Few individual humans last longer than 100 years. If we view the linguistic system as housed in individuals, then how do we account for change in languages over centuries of history?

The standard solution in the analysis of language change is to treat "the language" as the unit of analysis, and the site of the relevant mechanisms. However, given the fact that there are no empirically definable entities called "languages", as discussed above, this cannot give us a satisfactory account. It would leave us with a black box in the explanation, which requires its own explanation (Hedström and Swedberg 1998). In accordance 
with the doctrine of methodological individualism, the analysis of linguistic change must take the individual speaker as its ultimate unit of analysis, since language changes are not mutations of an organism but socially distributed innovations. The process takes place at the micro-level.

\section{An example from mainland Southeast Asia, Part 1}

I am going to illustrate how language change and areal diffusion take place where the individual is the unit of analysis. The example I use comes from a detailed case study of areal grammaticalisation across the mainland Southeast Asia area (Enfield 2003). Many languages of Southeast Asia such as Lao (Southwestern Tai), Vietnamese (Eastern Mon-Khmer), and Hmong (Hmong-Mien), show a particular pattern of grammatical polyfunctionality involving a verb with a basic meaning 'acquire', along the following schematic lines (where the relevant lexical item - e.g. $d a j^{4}$ in Lao - is represented here by $\left.{ }^{* * *}\right)$ :
a. transitive verb 'acquire'
John ${ }^{* * *}$ money $=$ 'John got some money'
b. intransitive verb 'succeed'
John sit test $* * *=$ 'John passed the test'
c. postverbal modal of ability
John go market *** = 'John can go to the market'
d. postverbal descriptive/adverbial complement marker
John go market ${ }^{* * *}$ two times $=$ 'John went to the market twice'
e. preverbal grammatical marker of 'achievement'
John ${ }^{* * *}$ go market $=$ 'John did go to the market'

The languages concerned belong to five different language families. The situation is typical of areal linguistics (Emeneau 1956; Gumperz and Wilson 1971; Heath 1978; Thomason 2000; Aikhenvald and Dixon 2001). The languages do not share this complex pattern due to common inheritance from an ancestor language. Possible reasons why two of these languages share this pattern are first, that they have independently made the same innovations by system-internal processes, and, second, that they have adopted features of the pattern by system-external processes, namely borrowing through contact (cf. Thomason and Kaufman 1988; Thomason 2001). Both 
of these possibilities assume "languages" as the basic unit of analysis of the process. It is assumed that it is "the language" which has innovated, or which has borrowed something from another language.

I have already discussed a number of problems arising from use of the term system with reference to languages. How can a language change or borrow something if it is not an independent entity? Once we have acknowledged that to speak of "languages" is to use a convenient shorthand (for something which needs to explicitly take into account the role of the individual speaker), then, if we are interested in seriously understanding processes such as those we so naturally think of as a language changing or a language affecting another language, we must ask how the process can be understood taking the individual as the fundamental unit of analysis. How do changes we conceive of as having taken place on the macro-level actually get played out in reality at the micro-level? How could the pattern of polyfunctionality illustrated in (1), above, have developed in language after language across mainland Southeast Asia?

\section{The bridging context mechanism in semantic change}

Let us consider just two features of the complex pattern described in (1) above, namely the intransitive verb 'succeed' and the postverbal modal meaning 'can', illustrated in ( $1 \mathrm{~b})$ and (1c). I have argued that in languages such as Lao, a postverbal modal meaning 'can' has developed out of a resultative usage of the verb 'succeed' (Enfield 2003: 125ff). Let me first describe the mechanism by which a new meaning of a single word can emerge. Let us call the source meaning (in this case a verb 'succeed') A and the output meaning (in this case a modal 'can') B. A simplest representation of meaning change looks like this (where $\rightarrow$ represents a passage in time):

(2) $\quad \mathrm{A} \rightarrow \mathrm{B}$

This figure represents the idea that at a certain time, a given form means A, and then at a certain time thereafter, it means B. As Sweetser (1990: 9) argues, however, this suggests an unrealistic scenario in which a whole population wakes up one day and starts to use a given word with a new meaning, suddenly dropping the old meaning. She argues that at the very least we need to postulate an intervening period of polysemy or multiple meaning, 
as follows (where A,B represents a period of time in which both A and B are distinct meanings denoted by the form in question):

$$
\mathrm{A} \rightarrow \mathrm{A}, \mathrm{B}(\rightarrow \mathrm{B})
$$

As the diagram shows, after the period in which the form has two distinct meanings - A and B - the old meaning may then be lost, leaving only the $B$ meaning. Evans and Wilkins (2000) (also Evans 1992, 1997; Wilkins 1996) have argued that the intervening period of multiple meaning represented in (3) as A,B needs to be understood more explicitly as including an initial period in which the new meaning, $B$, arises first not as a separate semantically encoded meaning but as the result of pragmatic enrichment through context-specific inference, only after which can it enter a period in which the said inference becomes a genuinely separate meaning. This is illustrated in the following diagram (where $A+>B$ means that $B$ is a defeasible pragmatic inference from $\mathrm{A}$ ):

$$
\mathrm{A} \rightarrow \mathrm{A}+>\mathrm{B} \rightarrow \mathrm{A}, \mathrm{B}(\rightarrow \mathrm{B})
$$

Crucial to this account is the notion of bridging context, i.e. a speech context in which something inferable as utterance-meaning from an input sentence-meaning happens also to be true, and thus not defeasible in that context. Defeasibility serves as a test for distinguishing between the status of some part of an utterance-meaning as inference rather than encoded meaning (Grice 1975; Levinson 2000). This test is not only useful for linguists, but also for speakers (assuming a view of meanings as individually constructed hypotheses, constantly tested in interaction, as outlined above). If speakers so often use a term in a context in which a certain possible inference is not defeasible (since it is true in that context), they seldom get to see the inference actually defeated, and thus become more likely to view the added meaning as part of the encoded meaning. Crucially, in such a context, which bridges from $\mathrm{B}$, as mere inference from $\mathrm{A}$ in context, to $\mathrm{B}$ as a context-independent separate meaning to $A$, it makes no difference if the two interlocutors involved have different internal conceptual representations of the status of $B$. When the right context is a commonly occurring one, speakers in a community can slip across from the $A+>B$ stage to the A,B stage in (4) unseen, one at a time, thus getting around the whole-community-changes-overnight problem pointed out by Sweetser (1990). 


\section{An example from mainland Southeast Asia, Part 2}

As a basis for a system-internal explanation for a given case of semantic change, the bridging context schema works well. Let me illustrate with reference to an example from Lao, introduced in abstract form in (lb) and (1c) above. I have suggested elsewhere (Enfield 2003) that the Lao word $d a j^{4}$ went from a stage in which it functioned as a main intransitive verb meaning 'succeed' to a stage in which it had a postverbal modal meaning 'can' (cf. Enfield 2003 for details). The proposed process presupposes the existence in the language of a certain construction with certain properties, namely a resultative construction of the form $\mathrm{V} 1-\mathrm{V} 2$, in which a verb phrase (V1) is followed by an intransitive verb (V2), such that V2 expresses the result of the event referred to in V1. There is no overt morphological marking of the resultative relationship between the two verbs. An important additional property of this construction is that in the absence of any modality/aspect marking, it may receive either a realis or potential reading. This is illustrated in the following example, which may take two interpretations, (i) and (ii) (the relevant resultative combination is $t o k^{2} t a a j^{3}$ 'fall die'):

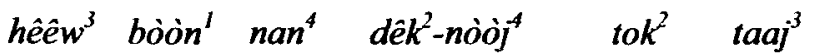

$$
\begin{aligned}
& \text { cliff place that child fall die }
\end{aligned}
$$

i. '(At) that cliff, a child fell and died.' (realis reading)

ii. '(At) that cliff, a child could/would fall and die.' (potential reading)

The potential reading in (ii) is introduced by a regular constructional alternation which arises for all such resultative constructions, regardless of the semantics of the verbs involved. The verb $d a j^{4}$ 'succeed' functions like other verbs which occur in the V2 resultative position, showing the regular realis versus potential alternation:

$$
\begin{aligned}
& \operatorname{man}^{2} \quad \text { seng }^{3} \quad \text { daj' }^{4} \\
& \text { 3SG sit.exam succeed } \\
& \text { i. 'He passed the exam.' (i.e. 'He sat the exam with success.') } \\
& \text { ii. 'He could/would pass the exam.' (i.e. 'If he sat the exam, he } \\
& \text { would succeed.') }
\end{aligned}
$$

There are various sub-types of resultative construction, depending on the aspectual structure of the V1 element (Enfield 2003: 120). When the first 
verb in such a construction includes a specification of its own result (e.g. a verb such as khaa 'kill'), a bridging context arises for the development of a meaning 'can' from the meaning 'succeed'. While a verb such as sêng ${ }^{3}$ 'sit an exam' does not entail a result (i.e. of passing the exam), the verb $k h a a^{5}$ 'kill' does include reference in its internal semantics to a result of some action, namely the death of an undergoer. When $d a j^{4}$ 'succeed' appears as a resultative complement of a verb such as khaa 'kill', it does not add a resulting event, but merely reiterates the resulting event already specified in the internal semantics of khaa 'kill':

$$
\begin{aligned}
& \operatorname{man}^{2} \quad \mathrm{khaa}^{5} \mathrm{khon}^{2} \text { nan }^{4} \quad \mathrm{daj}^{4} \\
& \text { 3SG kill person that succeed } \\
& \text { 'He killed that person with success.' (= 'He killed that person.') }
\end{aligned}
$$

The addition of a resultative verb meaning 'succeed' does not add anything to the basic event structure of the first verb khaa 'kill'. By contrast, the combination [sit.exam] + [succeed] in (6) allows a reading 'sit exam with success' (i.e. 'pass the exam', a meaning quite distinct from mere completion of the first verb 'sit the exam'). The combination [kill]+[succeed] results in the reading 'kill with success' (i.e. kill and cause to be dead, a meaning not distinct in event structure terms from mere completion of the first verb meaning 'kill'). When example (7) receives a potential reading, the presence of $d a j$ is equivalent to a modal 'can'. The potential reading is a property of the construction, but since in this case, the second verb is not adding anything to the event structure, then it is open to reanalysis as the marker of that constructionally derived modal meaning. This is how $d a j^{4}$, a verb meaning 'succeed', came also to have a meaning 'can' in a particular position.

\section{From micro-process to macro-process}

The bridging context account discussed in the previous section appears to provide a satisfactory system-internal account for the process, in terms of mechanisms established in research on grammaticalisation (cf. e.g. Hopper and Traugott 1993; Harris and Campbell 1995). The crucial feature of the explanation as I have presented it here is the bridging context. That this account simultaneously refers to a speaker's internal grammatical system and to a real-time situated interactional speech context opens up the ques- 
tion of exactly what is meant by a system-internal process in semantic change anyway. If the system is individual-situated, then part of the process is system-internal, but part of the process goes beyond this micro-level system. Processes driven at the micro-level must be linked to the macro-level if they are going to be actualized community-wide. Observable language change is a social innovation and innovations are socially distributed. The point holds with respect to language change (Keller 1994; Croft 2000; Enfield 2003), as well as for language maintenance. As researchers on social innovation have well documented (Rogers 1995), this is a process which must take the individual as its ultimate unit of analysis (Gladwell 2000). In other words, although something must happen on the private level for language diffusion and change to occur, the process by which an innovation becomes communal convention is a public one. And how this process takes its course is determined to a large extent by the highly textured nature of a given society (Enfield 2003: 8-19).

Beyond the question of how the modal meaning of $d a j^{4}$ could have emerged in the historical community of Lao speakers, we must also consider the areal perspective. The alternation I have described for Lao is also observed in dozens of other languages of mainland Southeast Asia. How could they have all become alike? Researchers of linguistic area phenomena have repeatedly documented this kind of situation, in which languages which are not genetically related nonetheless show a high degree of parallel structure (Thomason 2000, 2001). But it is not the case that the languages affect each other. The relevant processes are conducted by individuals in real-time situated interactions distributed across geographical space and historical time. The processes of linguistic diffusion and change are airborne. This goes even for those processes thought of as involving the bilingual brain (Romaine 1995: 78ff), since the outcomes of such processes cannot become new conventions without being diffused socially (Rogers 1995).

\section{Conclusion}

To understand the nature of linguistic systems, including their maintenance and change, it is crucial to consider them simultaneously both as something embodied in the individual and as being played out and observable in the larger social context. While it is only at the micro-level that the processes which apply to language actually take place, the consequences of these 
processes aggregate and conventionalize at the macro-level. While the micro- and macro-dimensions of language have traditionally been studied separately, within separate linguistic traditions, the two are interdependent and inextricably linked in reality, as they should be in our analyses of maintenance and change in linguistic systems.

\section{Notes}

1. Another opposition of micro- to macro- concerns the relationship between individual linguistic signs or items (e.g. specific words and constructions; Hudson 1996; Nettle 1999) at the micro-level, and the Saussurean system as a whole, with its paradigms and syntagms and sets of oppositions, at the macrolevel. Here, again, we must ask how the individual components relate to the larger entity assumed to exist at the macro-level.

2. One cannot object to this claim by countering that the written word provides just such evidence. This is because in themselves, written words are mere ink patterns. They are tokens of signifiers, which mean nothing until they are interpreted by someone to be signifying some signified. And no signified exists outside a mind beholding the signifier: "A Sign is a representamen of which some interpretant is a cognition of a mind" (Peirce [1932] 1965: 142, emphasis added).

\section{References}

Aikhenvald, Alexandra, and Robert M.W. Dixon (eds.)

2001 Areal Diffusion and Genetic Inheritance: Problems in Comparative Linguistics. Oxford: Oxford University Press.

Apresjan, Juri D.

1974 Regular polysemy. Linguistics: An International Review 142: 5-32.

Clark, Herbert $\mathrm{H}$.

1996 Using Language. Cambridge: Cambridge University Press.

Croft, William

2000 Explaining Language Change: An Evolutionary Approach. Harlow: Longman.

Emeneau, Murray B.

1956 India as a linguistic area. Language 32: 3-16.

Enfield, Nicholas J.

2003 Linguistic Epidemiology: Semantics and Grammar of Language Contact in Mainland Southeast Asia. London: Routledge Curzon. 
Evans, Nicholas D.

1992 Multiple semiotic systems, hyperpolysemy, and the reconstruction of semantic change in Australian languages. In Diachrony Within Synchrony: Language History and Cognition, Günter Kellerman and Michael D. Morrisey (eds.), 475-508. Frankfurt am Main: Verlag Peter Lang.

1997 Sign metonymies and the problem of flora-fauna polysemy in Australian linguistics. In Boundary Rider: Essays in Honour of Geoffrey $O$ 'Grady, Darrell Tryon and Michael Walsh (eds.), 133-153. (C136) Canberra: Pacific Linguistics.

Evans, Nicholas D., and David P. Wilkins

2000. In the mind's ear: The semantic extensions of perception verbs in Australian languages. Language 76 (1): 546-592.

Gladwell, Malcolm

2000 The Tipping Point: How Little Things Can Make a Big Difference. Boston: Little, Brown.

Grice, H. Paul

1975 Logic and conversation. In Syntax and Semantics 3: Speech Acts, Peter Cole and Jerry L. Morgan (eds.), 41-58. New York: Academic Press.

Gumperz, John, and Robert Wilson

1971 Convergence and creolization: A case from the IndoAryan/Dravidian border in India. In Pidginization and Creolization of Languages, Dell Hymes (ed.), 151-167. Cambridge: Cambridge University Press.

Harris, Alice C., and Lyle Campbell

1995 Historical Syntax in Cross-linguistic Perspective. Cambridge: Cambridge University Press.

Heath, Jeffrey

1978 Linguistic Diffusion in Arnhem Land. Canberra: Australian Institute of Aboriginal Studies.

Hedström, Peter, and Richard Swedberg (eds.)

1998 Social Mechanisms: An Analytical Approach to Social Theory. Cambridge: Cambridge University Press.

Hopper, Paul J., and Elizabeth C. Traugott 1993 Grammaticalization. Cambridge: Cambridge University Press.

Hudson, Richard A.

1996 Sociolinguistics. (Second edition.) Cambridge: Cambridge University Press.

Hutchins, Edwin, and Brian Hazlehurst

1995 How to invent a shared lexicon: The emergence of shared formmeaning mappings in interaction. In Social Intelligence and Interac- 
tion, Esther N. Goody (ed.), 53-67. Cambridge: Cambridge University Press.

Keller, Rudi

1994 On Language Change: The Invisible Hand in Language. London/New York: Routledge.

Le Page, Robert B., and Andrée Tabouret-Keller

1985 Acts of Identity: Creole-based Approaches to Language and Ethnicity. Cambridge: Cambridge University Press.

Levinson, Stephen C.

2000 Presumptive Meanings: The Theory of Generalized Conversational Implicature. Cambridge, Mass.: The MIT Press.

Lewis, David

1969 Convention. Cambridge, Mass.: Harvard University Press.

Lukes, Steven

1968 Methodological individualism reconsidered. British Journal of Sociology 19: 119-129.

Nettle, Daniel

1997 On the status of methodological individualism. Current Anthropology 38 (2): 283-286.

1999 Linguistic diversity. Oxford: Oxford University Press.

Peirce, Charles S.

1965 Collected Papers of Charles Sanders Peirce (Volume II: Elements of Logic), edited by Charles Hartshome and Paul Weiss. Cambridge, Mass.: The Belknap Press of Harvard University Press. First published in 1932.

Rogers, Everett $M$.

1995 Diffusion of Innovations. (Fourth edition.) New York: The Free Press.

Romaine, Suzanne

1995 Bilingualism (second edition). Oxford: Blackmore.

Schelling, Thomas C.

1960 The Strategy of Conflict. Cambridge, Mass.: Harvard University Press.

Smith, Adam

1976 An Inquiry into the Nature and Causes of the Wealth of Nations. Oxford: Clarendon Press. First published in 1776.

Sweetser, Eve

1990 From Etymology to Pragmatics: Metaphorical and Cultural Aspects of Semantic Structure. Cambridge: Cambridge University Press.

Thomason, Sarah G.

2000 Linguistic areas and language history. In Languages in Contact, Dicky Gilbers, John Nerbonne, and Jos Schaeken (eds.), 311-327. Amsterdam: Rodopi. 
2001 Language Contact: An Introduction. Edinburgh: Edinburgh University Press.

Thomason, Sarah G., and Terrence Kaufman

1988 Language Contact, Creolization, and Genetic Linguistics. Berkeley: University of California Press.

Wilkins, David

1996 Natural tendencies of semantic change and the search for cognates. In The Comparative Method Revisited, Mark Durie and Malcolm Ross (eds.), 264-304. New York: Oxford University Press. 